\title{
Study on Architectural Ornament Images of Wuzhou Arcade Buildings*
}

\author{
Yang $\mathrm{Yu}$ \\ Wuzhou University \\ Wuzhou, China
}

\author{
Li Jiang \\ Wuzhou University \\ Wuzhou, China
}

\begin{abstract}
This paper, taking the architectural ornament images of Wuzhou arcade buildings as the breakthrough point, conducts systematic research on the applied themes, means of composition, material carriers, process and accessorial components, techniques of expression and the influence of culture on architectural ornament images through literature researches and field investigation, with the expectation of providing a certain theoretical and referential value for the protection, renewal and development of Wuzhou arcade buildings.
\end{abstract}

Keywords—arcade buildings; architectural ornament; images

\section{INTRODUCTION}

Arcade buildings, an architectural form in the modern China's South-East coastal areas oriented to commercial and residential functions, are originated from the imitation of Guangzhou urban construction mode proposed by Xijiang's rehabilitation supervisor Li Jishen depending upon the concept of replacing ramparts with roads and building arcade streets. Having experienced the development for nearly a hundred year, this sort of buildings, on the one hand, carried historical memory of the city evolution; on the other hand, were confronted with conflicts between the structure safety/the adaptation to building functions and modern pattern of life; therefore, attention are attached by governments, community residents, historical buildings preservation specialists and scholars on a variety of social issues triggered by arcade buildings.

\section{RELATED CONCEPT DEFINITION}

\section{A. Architectural Ornament}

Architectural ornament is not only the outward manifestation by architecture of politics, economy, geography, history and culture under a specific society and historical period, but a decorative behavior with group consciousness and aesthetic tastes created by laboring people and closely related to their production, life, conventions and customs, religious ideas and moral principles, which is used for conveying their aesthetic requests for architectural ornaments and hope for

*Fund Project: 2015 Youth Fund Project for Humanistic and Social Science Research of Ministry of Education (15YJC760121); 2016 Basic Ability Enhancement Project for Young and Middle-Aged Core Teachers in Guangxi (KY2016YB431); 2014 General Science and Technology Research Protect for Guangxi Universities (YB2014370); Wuzhou University Schoollevel Scientific Research Project in 2014 (2014C008). good life.

Architecture noumenon decides the tectonic forms; it generates functional decors and additive decors out of the relationship between architectural ornaments and architecture noumenon; the former refers to ways of adorning the tectonic forms of architecture noumenon; while the latter is designed to append to the outside noumenon for the purpose of beauty.

\section{B. Image}

Images, a nonverbal visual sign, act as the information medium to realize the ideological communication and emotional exchanges between humans and objects or among humans on the social common sense basis.

Researches on architectural ornament images should never be confined to the superficial visual signs (e.g. styles, colors or materials, etc.), but dispel the mist of visual signs to discover concealed concepts and ideas. "They play the role of signs in a particular situation and can only function in this case." [1] Therefore, architectural ornament images should be investigated under particular historical context and situation to further explore the implied symbolic significance of cultural conventions, social habits, aesthetic characteristics and ethnic culture, etc.

\section{CARRIER, PROCESS AND THEME OF ARCHITECTURAL ORNAMENT IMAGES}

(1) Grey model - refers to a specific architectural ornament art of the South of Five Edges, principally prepared by lime or shell-lime mixed with straw and rough straw paper to make emplaster used for portraying or moulding architecturally; or generating various graphic patterns, landscape and figures as a sort of decorative effects; grey models, being popular, easy to understand, and provided with aesthetic perspective suiting both refined and popular tastes, is capable of creating sensual pleasures for affability and cheer.

Also, grey molds extracted, purified, dried and shaped are characterized by high strength, acid resistance, moisture resistance, thermostability and long service life, etc. allowing it to suit the climatic features of humidity and torridity in the South of the Five Edges where grey molds are widely applied.

Grey molds are mainly applied in the pediment ornaments for the arcade buildings in Wuzhou, abundantly themed by landscape, animals, plant and characters; lively expressed by 
embossment and circular engravure, etc.; painted colorfully for auspicious symbols; e.g. fishes imply "May you always get more than you wish for" and "abundant wealth or many children in the family"; a white crane symbolizes longevity and youth; a couple of mandarin ducks stands for living together forever in conjugal bliss and love; a paradise flycatcher is regarded as a mascot of longevity and happiness; horses usually emblem ceaseless self-improvement, aggressiveness, positivity, pursuit and success immediately upon arrival; a peacock is considered the embodiment of luck, goodness, beauty and dignity "Fig. 1".
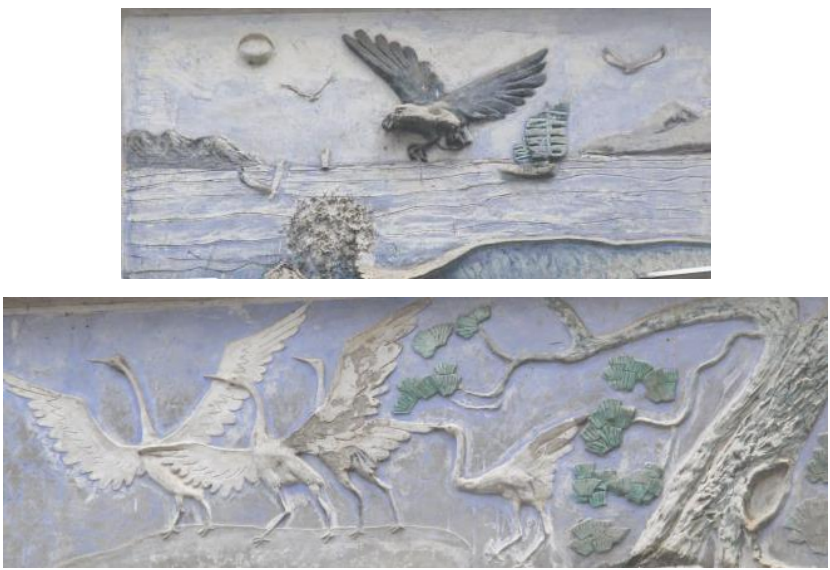

Fig. 1. Sample of grey model on arcade pediment

(2) Embossment is an artistic expression between painting and circular engravure by plane engraving attached to certain carriers. The spatial forms of an embossment fall in between the two-dimension virtual space of painting and the threedimension physical space of circular engravure, so it allows more than full play to advantages of painting in composition, spatial process, subject selection, scene manifestation, viewpoint switch, background \& environment creation, etc., but is different in approach but equally satisfactory in aesthetic images reflected by circular engravure, mainly applied in the pediment ornaments for arcade buildings and decorative tips for breast, windows or walls, etc. "Fig. 2".
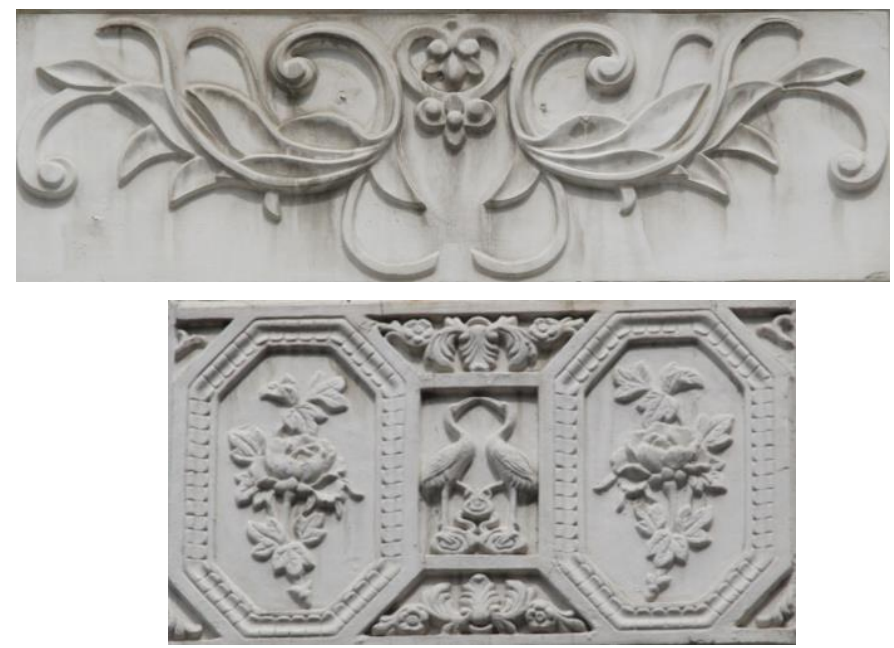

Fig. 2. Sample of embossment on arcade
(3) Stone carving refers to using stones as the raw materials to sculpture and create visual images, so as to reveal the aesthetic implication, aesthetic orientation, aesthetic habits and traditional culture contained by patterns. Thanks to stiffness, wear and corrosion resistance, weather resistance and long existence of stones, stone carving plays a significant role in the ornaments for memorial archways of arcade buildings in Wuzhou. In the middle top of the memorial archway the pattern "two dragons playing a pearl" is engraved, on the one hand, to indicate two dragons rising rapidly to the sky and all things on earth overflowing with vigor, and on the other hand, to imply the respect, value and cherishment of the ancients for life, in addition of cognition, comprehension and expression of biological phenomena ceaselessly inherited from generation to generation "Fig. 3".

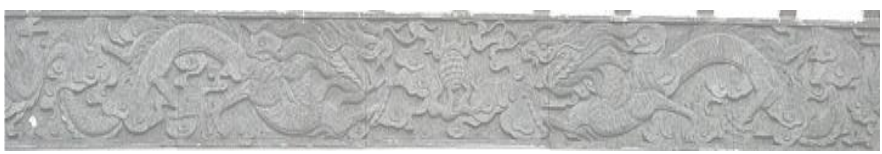

Fig. 3. Sample of stone carving on memorial archway

The decorated brackets for memorial archways adopt a traditional Chinese auspicious animal - dragon, which shows the divinity, including being fond of water and flying, accessing to the heaven, capricious, supernatural, auspicious, ominous and formidable, etc.; thus, such symbolic meanings as wisdom and power are endowed to dragons. Besides, dragon is the representative of Chinese nation and the symbol of China. On the front and back of the memorial archway three calf elephants are engraved, standing for "everything takes on a completely new look". The keel blocks of four pillars are carved by the patterns of "prosperity brought by the dragon and the phoenix" and "birds paying homage to the phoenix", implying the prosperous nation of wealthy people, harmony between Yin \& Yang, happiness and blessing.

\section{EXPRESSION TECHNIQUES OF ARCHITECTURAL ORNAMENT IMAGES}

The expression techniques of architectural ornament images mainly include homophony, symbol and metaphor, which means, building decorative images take homophony as the medium to build the symbolizing and symbolized relationship between visual images and cultural connotations, and to express psychological desires and spiritual appeals for blessing and luck by means of metaphor [2].

A symbol is the expression of an abstract concept, thought, or emotion using the relationship between the body object and the symbolic object. German scholar Cassirer argues that "a symbol is to show the symbols in the inner spiritual world through the symbols in the outer world, or to transit the symbols from the visible material world to the symbols in the invisible world [3].

A metaphor is to hide the original meaning behind a certain marker or through a metaphor to reflect the symbol of a certain faith circuitously.

Symbol and metaphor, while having commonality, for instances, in composition - a symbol consists of two parts: 
body object and symbolic object and a metaphor consists of two parts: body object and metaphorical object; in producing method of meanings, both symbol and metaphor are implied by the expression of another thing; however, largely differ in the expression ways of architectural ornament images. According to Zhu's view [4]: the difference between symbol and metaphor is mainly manifested in three aspects: A symbol points out a view, while a metaphor highlights specific objects; the meaning of a symbol is rational, while the meaning of a metaphor is related; a symbol pursues the subjective and complete consciousness, while a metaphor focuses on the specific feelings and experiences of a subject; that is, the image and meaning in a symbol itself do not have a necessary connection and their relationship is coincident; while a metaphor needs to seek similarity from the body object and its metaphorical objects.

For architectural ornament images of arcade buildings in Wuzhou, in terms of symbolic expression, elephant symbolizes "everything takes on a new look"; horse stands for ceaseless self-improvement; dragon represents China and power. In terms of metaphor, fruitful grapes pray for good harvests; and polycaryoptic grapes stand for "many sons and grandsons"; Pine means longevity due to its long life; in addition, due to no fear of cold, pine also means unyielding spirits; Crane is an auspicious beast with long life, so it is a symbol of longevity; Bamboo with sections are considered moral and honorable; besides, the hollowness of bamboo symbolizes modesty. The traditional famous flower - peony has the beauty of color, fragrance and charm, representing wealth and prosperity; in ancient times, magpie was known as the "goddess" with the ability to perceive omens, so magpie is a magical implication of incoming happy events. In homophony, “瓶” (ping, bottle) has the same pronunciation with "平" (ping, peace), so bottles become a symbol of peace; “荷” (he, lotus) has the same pronunciation with "和" (he, peace/harmony), so lotus is also a symbol of peace; “鱼” (yu, fish) has the same pronunciation with “余” (yu, yield), so fishes are used to pray for good yields over years.

\section{INFLUENCE OF CULTURE ON ARCHITECTURAL ORNAMENT IMAGES}

\section{A. Auspicious Culture}

Traditional Chinese auspicious culture is cradled by the ancients' original totemism of nature; to survive and reproduce, to pray for the nature's "forgiveness" and "gift", it thereupon becomes an instinct for hominids to ward off evil spirits and seeks for lucks; continuously improved in Tang and Song dynasties, auspicious culture is increasingly mature and at the height of splendors [5] by Ming and Qing dynasties when the sacrifice and pray rites and witchcrafts represented by language or character, along with all sorts of traditional auspicious patterns, textures and decors[6] with propitious omens, are created to show auspicious ideas.

Traditional Chinese auspicious decorative elements are derived from sedimentary deposits of Chinese ethnic culture for thousands of years, rooted in the group aesthetic consciousness formed by Chinese traditional society structure and cultural structure, and based on the plain folk custom of laboring people. Auspicious culture is a phenomenon infused with intense subjective colors and requires specific technique of expression to signify subjective beautiful wishes [7]; moreover, the architectural ornament vocabularies of Wuzhou arcade city, recurring to supernatural beings, flowers and plants, auspicious birds and beasts, as well as letter symbols, by means of homophony, symbol and metaphor, a large number of exquisite works of relief works were created through the craftsmen of the craftsmanship to express the spiritual sustenance and good wishes of working people towards auspicious life, which were the accumulation of psychological needs and psychological association[8]; Auspicious decorative themes and elements have built a deep association between architectural decorations and the existence of human ontology.

\section{B. Harmonious Culture}

After the opening of Wuzhou as a commercial port in 1897, the western culture representing modern industrial civilization poured into the traditional Chinese culture representing agricultural civilization. However, the buildings of Wuzhou arcade city are neither just the transplant or copy of Western architectural style, nor a sort of eisegesis of the Western architectural decorative vocabulary; but a new architectural cultural pattern formed in the shock and integration process of traditional Chinese architectural culture and Western architectural culture by retaining the functionality of traditional Chinese architecture and architectural decoration patterns or elements, in addition to absorbing and integrating Western architectural style and decorative vocabulary. Therefore, the urban culture presents the duality of tradition and modernity, agricultural civilization and industrial civilization, local culture and foreign culture opposite and interweaved [9].

\section{1) Baroque architectural style}

Baroque architecture rises in the 17th century of Italy and is characterized by freedom of style, complex shape, pursuit of dynamic, luxuriant decoration and exquisite carving. Wuzhou arcade architectural decoration, besides the imitation of Baroque style, adds the Baroque pediment ornaments on the basis of the overall stable façade composition (for example No. 42 Guibei Road).

\section{2) Classical architectural style}

Classical architectural style develops based on the ancient Greek architecture and ancient Roman architecture, mainly manifesting in the classic order composition and highlighting the axis, symmetry, proportion and master-slave relation.

Wuzhou arcade building facade mainly applies the classical three-stage treatment that is bottom colonnade, middle wall and top pediment in the vertical three-stage pattern or the horizontal bilateral symmetry composition.

In the capital processing, the arch-style colonnade uses simplified ionic capital and composite column capital styles. This kind of noumenal ornaments derived from the ancient Roman period (to solve the contradiction between column type and arch structure) has now evolved into an additional decorative elements, and arch by this way has become an important component of the arcade building facade decoration. 
In the scape processing, it is relatively simple compared with the classical order and abandons the treatment of classical scape on proportion, carving and other details, replaced by a flat and pictorial order processing.

As the main body of the arcade building, the floor wall is mainly composed of window, window head, pier between two windows, buttress, decorative column, water gate, balcony and other parts to constitute the arcade facade form combining diversity and unity. The window and the water gate are decorated in a classical style with window head, lintel and decorative columns; in addition, the buttress, which was functionally decorated to increase the strength and rigidity of the walls, has now been converted into an additional decoration. Decorative column and buttress in the arcade facade composition are flexible and capable of space division, spacing adjustment and increase of decorative aesthetics; the columns follow the classical style but tend to be simplified and flatten.

\section{3) Nanyang style}

Opening one or more holes in round or other shapes on the parapet is a very unique and creative form in the Nanyang region; this is a previous technical treatment for preventing strong typhoon attacks in the Nanyang area and reducing wind load of buildings, thus forming a unique form of architectural art (for example No. 16 Guibei Road).

\section{4) Modern style}

Modern style arcades have obvious distinctions with the traditional arcades in scale, structure, materials, modeling style and other aspects. In general, the facade uses simple, bright, practical functionalism treatment, instead of complex decorations. For instance, the cornice skintle of beam-pillar colonnade is evolved and transformed from the western complex mode to the modern simple mode. In the dynamic process of Chinese and Western architectural culture fusing and conflicting, Wuzhou arcade building components architrave, just like pillars and beams, has now been converted into an additional decoration after de-functioning (horizontal components for linking two columns and bearing load); the form continues the charm of traditional Chinese architectural decorations, but the shapes of architrave skintle have gradually become modernly simple and plain.

\section{5) Traditional Chinese style}

The form of the arcade continues the characteristics of the traditional houses in the south of China; the building body is built in brick structure or brick-wood structure; generally two or three windows (few opens one window due to a narrow face width, for example No. 71 Xiaonan Road) are arranged in the front wall of the floor.

Two opening windows are the same in size; for three windows, it includes two forms: three windows in the same size or one bigger and two smaller (the middle one is bigger than the windows on the both sides). In Wuzhou, if opening three windows, it mainly uses three windows in the same size, but rarely selects the form of one bigger and two smaller (for example No. 39 Nanti Road). Some windows, such as Manchu window composed of pieces of small colored glasses (e.g. No. 16 Dazhong Road), basically have no decoration on the façade.

\section{CONCLUSION}

Wuzhou arcade buildings are produced and developed under the multicultural background of modern times. Building decoration is the product of culture and the human spirits; architectural ornament images, as the culture symbol under specific political, economic, cultural context, carry a deep cultural significance. Decorative images for Wuzhou arcade buildings present the multicultural and artistic features integrating Chinese traditional culture and western modern culture in the subject matters, composition forms, material carriers and performance methods of architectural ornament images. The research on the architectural image of Wuzhou arcade will play a useful role in constructing the framework system of Wuzhou arcade building research, and provide some theoretical and reference value for the protection, renewal and development of Wuzhou arcade building.

\section{REFERENCES}

[1] E.H. Gombrich, edited by Yang Siliang, Fan Jingzhong. Emblematical Images [M]. Shanghai: Shanghai Painting and Calligraphy Press, 1990.

[2] Huang Tao. Homophonic Symbols and Propitious Folkways[J]. Journal of Hebei University (Philosophy and Social Sciences Edition), 2006 (2): $14-19$.

[3] Ernst. Cassirer. An Essay on Man[M]. Shanghai: Shanghai Translation Publishing House, 1985

[4] Zhu Qianguo. Discussion on the Relationship between Metaphor and Symbol [J]. Journal of Jishou University (Social Sciences Edition), 2007(4): 167-169.

[5] Wang Hailin. Innovative Application of Traditional Auspicious Patterns in Modern Design [J]. Packaging Engineer, 2011, 32(14):8-11.

[6] Zhou Xing. Traditional Chinese Auspicious Patterns as Folk Art Heritage [J]. National Art, 2005(1):52—66.

[7] Xu Hualong. Chinese Propitious Culturalism [J]. Journal of Guangxi University for Nationalities (Philosophy and Social Sciences Edition), 1999(1):67-71.

[8] Hu Zhenjiang. Innovative Applied Analysis of Traditional Auspicious Patterns in Modern Design [J]. Packaging Engineering, 2013, 34(4):101-104.

[9] Tu Wenxue. Opposition and Coexistence: Dual Structure of Modern Urban Culture in China [J]. Tianjin Social Sciences, 1998(1):107-112. 